\title{
Influence of Microstructural Changes on Residual Stress Characteristics and Macro-Hardness of Submerged Arc Welded P-91 Steel Plates
}

\author{
Raja Chakrabarti ${ }^{1}$, Joydeep Roy ${ }^{2}$ (D), Pankaj Biswas ${ }^{3}$, Subhas Chandra Saha ${ }^{2}$ \\ ${ }^{1}$ Tripura Institute of Technology, Department of Mechanical Engineering, Agartala, India. \\ ${ }^{2}$ National Institute Technology Agartala, Department of Mechanical Engineering, Tripura, India. \\ ${ }^{3}$ Indian Institute Technology Guwahati, Department of Mechanical Engineering, Guwahati, Assam, India.
}

How to cite: Chakrabarti R, Roy J, Biswas P, Saha SC. Influence of microstructural changes on residual stress characteristics and macrohardness of submerged arc welded P-91 steel plates. Soldagem \& Inspeção. 2021;26:e2601. https://doi.org/10.1590/0104-9224/SI26.01

\begin{abstract}
In this study, the submerged arc welded butt joint of P-91 ferritic-martensitic alloy steel plates has been chosen to examine the influence of microstructural changes on welding residual stress characteristics and macrohardness in the weldment with two different heat input $2497.5 \mathrm{~J} / \mathrm{mm} \& 2040 \mathrm{~J} / \mathrm{mm}$ respectively. The stress magnitudes at a different location on the welded specimen are measured by X-ray diffraction technique at the postweld heat-treated condition. Compressive stresses are observed in the weld zone (WZ) and tensile stresses are detected at the boundary of the heat-affected zone (HAZ) near the weld zone. Higher compressive stresses are found in the weld zone of both the specimens where maximum hardness values are observed. Different grain matrix in the microstructure contributes significantly towards the quality of weldment. Residual stress, as well as the hardness of weldment, is found to be influenced by the martensite phase transformation and dissolution of precipitates. A modeling concept is presented for dimensional analysis of martensite structure. Energy dispersive X-ray indicates the distribution of carbides at the grain boundaries. Optical micrograph substantiates the presence of $\delta$-ferrite in the WZ.
\end{abstract}

Keywords: Ferritic-martensitic alloy steel; Weld zone; Heat-affected zone; Microstructure; Martensite phase transformation; Macro-hardness; Welding residual stresses.

\section{Introduction}

Welding thermal cycle influences the microstructural changes in the weld region and heat affected zone which produces the welding residual stresses of different magnitudes in the welded structure [1]. The change in the microstructure is a matter of concern as it simultaneously affects the mechanical properties in the weldment. Between compressive and tensile residual stresses, particularly the later one can promote the detrimental effects in the structure in the form of hot cracks, cold cracks, creep rupture, etc [2]. The accurate prediction of welding residual stress characteristics in the welded part is still relevant in order to prevent the premature failure of fabricated components used in the different applied fields [3].

Submerged arc welding is a high energy welding process with appreciable welding speed in which the weld zone is completely covered with granular flux [4]. It creates an excellent quality of the weld and extensively used for joining thick steel plates in the applied field. The shape of the weld, as well as heat input related to this welding process, depends on the different process variables which can be controlled to get the desired joint [5]. During the submerged arc welding process, the weld area is heated up very sharply under the influence of welding heat input which cools down subsequently and generates residual stresses in the weldment [6]. The elements in the flux influence the quality of the WZ and Tanaka et al. have shown in a study that the amount of sulphur and phosphorous in the weld are decreased with the increase in basic oxides in flux [7].

Over the last few years, the P-91ferritic martensitic alloy steel has been extensively used in power generation industries for its excellent performance against creep failure at elevated temperature and pressure. Basically, modified $9 \mathrm{Cr}-1 \mathrm{Mo}$ steel is a newly developed alloy steel which has high thermal conductivity with low thermal expansion of coefficient and high strength [8]. Chromium and Molybdenum, being two major constituents, of this steel act as carbide former and ferrite stabilizer respectively. The small additions of $\mathrm{V}, \mathrm{Nb}, \mathrm{N}$ and other alloying elements in P-91 steel have considerably upgraded the service quality of this type of structural steel in the temperature region of $600^{\circ} \mathrm{C}$ comparing to earlier grades $\mathrm{P}-22(2.25 \mathrm{Cr}-1 \mathrm{Mo})$ steel [9]. The low temperature $\left(375^{\circ} \mathrm{C}-185^{\circ} \mathrm{C}\right)$ martensitic transformation in the weld zone of P-91 steel is an important phenomenon [10]. Moreover, the occurrence of type IV failure in such steel in the heat-affected-zone (HAZ), typically in ICHAZ, has limited its service life cycles which need a detailed investigation to minimize such failures. A study is conducted by Laha et al. on the type IV failure in P91 steel where the emergence of Z-phase during long service cycles at the elevated temperature is identified as

Received: 05 Feb., 2020. Accepted: 09 Dec., 2020.

E-mail: deeproymech@gmail.com (JR)

This is an Open Access article distributed under the terms of the Creative Commons Attribution Non-Commercial License which permits unrestricted noncommercial use, distribution, and reproduction in any medium provided the original work is properly cited. 
one of the most responsible factors [11]. In addition to phase transformation, the typical contribution of the precipitates (carbides, carbonitrides etc.) in the WZ and HAZ of P91 steel has made the microstructural study more significant. Golanski et al. have shown the benefits of boron inclusion in P91 steel developing a more stable nature of precipitates like $\mathrm{M}_{23}(\mathrm{C}, \mathrm{B})_{6}$ [12]. In a study conducted by Filemonowicz et al., it is seen that the different phases evolved out through microstructural changes that affect the creep properties of P-91steel[13]. A detailed analysis of the microstructure and mechanical properties is performed by Pandey et al. on the P91 steel pipe joint at different PWHT conditions. The joint is developed using V-groove and narrow groove by GTAW with multiple passes. While comparing the weldment of P91 steel at two different conditions (i.e PWHT and as-weld), a reduction in hardness is found with PWHT in FZ and HAZ. A change in microstructure is reported with a variation in post weld condition [14]. A relevant study has been conducted by Xiaotian et al. on the microstructure of modified $9 \mathrm{Cr}$-1Mo steel and the emergence of $\delta$-ferrite along with other important phases in WZ and HAZ is elaborately explained. The variation in hardness in a different zone of weldment is also addressed [15].

Generally, the magnitudes of residual stresses in weldment are measured by different destructive and non-destructive measurement methodologies [16-18]. Jian Lin et al. have measured the stress magnitudes in the lap joint of P92 steel by the XRD method [19]. The influence of martensitic transformation on residual stress in the weldment of P92 steel is examined by Suo Li et al. by hole drilling and XRD method [20]. As the distribution of welding residual stress in the weldment is complex and purely heterogeneous in nature over the length, it is complicated and costly to measure the variation in the stress field with respect to temperature gradient over a large area of interest by any experimental measurement technique. In a typical pipe joint of P-91steel, the development of residual stresses is examined by S. Paddea et al. in as-welded and post-weld heat treated (PWHT) conditions by neutron diffraction technique. The higher magnitudes of compressive stresses are noted in the as-welded condition in the outer surface of the pipe joint while it shows the tensile towards the inner surface with a peak of about $600 \mathrm{MPa}$ [21]. To understand the effect of two different submerged arc welding processes on welding residual stress, A. Ishigami et al. has measured longitudinal and transverse stresses by neutron diffraction technique [22]. A. Kundu et al. has conducted a typical study of residual stresses on the butt welded plates of P91steel by neutron diffraction technique and the maximum tensile stress is observed in HAZ with longitudinal direction [23]. An interesting study has been conducted by Venkata et al. to understand the effects of post weld heat treatment on the residual stresses of the butt welded P91plates through simulation and neutron diffraction technique. Residual stresses in the plates are found to be influenced by the time and the constant temperature at which the specimens are held during heat treatment process [24]. It is observed in a comparative study on residual stresses between P91 and austenite steel plates that the peak of tensile stresses exists at 10 $\mathrm{mm}$ distance from weld center line of butt welded P91plates [25]. Another motivating study has been carried out by V.Maduraimuthu et al.on the two types of welded joints in P91 plates, developed by the conventional TIG and TIG with activated flux. A high magnitude of compressive stresses with a peak of about 270MPa is reported in the WZ of the joint with activated flux [26]. The phenomenon of residual stress in the pipe-joint of P91 steel may be attributed to the tourniquet effect due to the shrinkage in circumferential region while the development of residual stresses in the butt welded plates does not exhibit the same effect due to the dissimilarities in the nature of joint and the same is elaborated later in section 4.4 [27] .

In the context of the mentioned literature, it reveals that the microstructural changes with respect to welding heat input in WZ and HAZ of P-91 steel are a very relevant study. It also appears that such changes greatly affect the residual stress characteristics and macro-hardness in the weldment of modified $9 \mathrm{Cr}$-1Mo steel. However, to date, this type of study is not performed to relate the influence of variation of heat input on stress characteristics and macro-hardness. In the practical field, it bears a significant role. Hence the investigation is carried out on submerged arc welded P-91 steel plates to examine the influences of microstructural evolution on the residual stresses and macro-hardness.

\section{Experimental Procedure}

Modified 9Cr-1Mo (P-91) steel has been chosen in this investigation as base metal and the desired samples of $150 \mathrm{~mm} x$ $150 \mathrm{~mm} \times 10 \mathrm{~mm}$ of square butt-joint are made having a $3 \mathrm{~mm}$ root gap to perform the welding as shown in Figure 1.The submerged arc welding machine is used for the welding of prepared samples of P-91 steel plates. Preheat is done on both the specimen of P-91steel at a temperature $200-250^{\circ} \mathrm{C}$ for a period of 1 hour in a muffle furnace and subsequent post-weld heat treatment $(\mathrm{PWHT})$ is performed at $760^{\circ} \mathrm{C}$ for $3 \mathrm{~h}$ with cooling up to room temperature in the furnace to achieve desired properties.

The type of electrode used in the welding operation is AWS.SFA. 5.23 EB9 with $3.15 \mathrm{~mm}$ diameter and the commercial flux used for the welding process is MAX flux SAF12. Table 1 shows the different constituents present in the P-91 steel plates and consumable wire as obtained through chemical analysis.

Table 1. Chemical composition (wt\%) of Base metal and filler wire.

\begin{tabular}{cccccccccccc}
\hline Element & $\mathbf{C}$ & $\mathbf{M n}$ & $\mathbf{P}$ & $\mathbf{S}$ & $\mathbf{C r}$ & $\mathbf{N i}$ & $\mathbf{M o}$ & $\mathbf{V}$ & $\mathbf{N b}$ & $\mathbf{A l}$ \\
P91 & 0.098 & 0.5 & 0.006 & 0.005 & 9.164 & 0.225 & 0.912 & 0.226 & 0.105 & 0.023 \\
\hline P91 wire & 0.102 & 0.432 & 0.014 & 0.006 & 8.985 & 0.221 & 0.845 & 0.210 & 0.087 & 0.015 \\
\hline
\end{tabular}



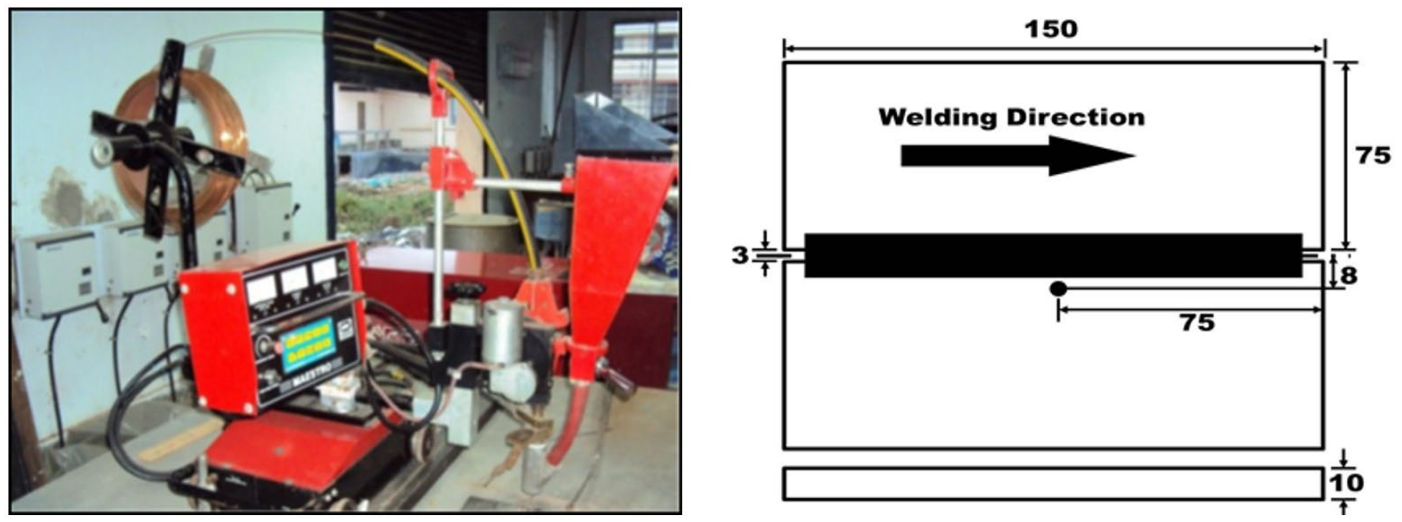

Figure 1. SAW- experimental setup and schematic presentation of the welded specimen(dimensions are in $\mathrm{mm}$ ).

The specimens of P-91 steel are butt-welded using two heat input of $2040 \mathrm{~J} / \mathrm{mm}$ and $2497.5 \mathrm{~J} / \mathrm{mm}$, marked as $\mathrm{H}_{1}$ and $\mathrm{H}_{2}$ respectively. The heat input values are derived from the following governing equation of heat generation of submerged arc welding process with the process parameters as depicted in Table 2.

$Q=\frac{\eta V I}{S}$

Where $Q$ is the amount of heat input $(\mathrm{J} / \mathrm{mm}), \eta$ is the heat transfer efficiency, $\mathrm{V}$ relates to welding voltage $(\mathrm{V})$, I indicates welding current $(A)$ and $S$ relates to welding speed $(\mathrm{mm} / \mathrm{s})$.

Table 2. SAW process parameters.

\begin{tabular}{cc}
\hline Parameters & Values \\
Standoff distance & $26 \mathrm{~mm}, 28 \mathrm{~mm}$ \\
\hline Welding speed & $6 \mathrm{~mm} / \mathrm{s}, 7.5 \mathrm{~mm} / \mathrm{s}$ \\
\hline Voltage & $37 \mathrm{~V}, 34 \mathrm{~V}$ \\
\hline Current & $450 \mathrm{~A}, 500 \mathrm{~A}$ \\
\hline
\end{tabular}

The thermocouples are used (K-type) on the upper surfaces of the samples to get the temperature profile of the weld thermal cycle through a data logger. Specimens of $20 \mathrm{~mm} \times 20 \mathrm{~mm} \times 10 \mathrm{~mm}$ are cut by wire electro-discharge machining (WEDM) and polished by different grades of emery paper followed by a fine finishing process using diamond paste on a selvyt cloth. Finally, the surfaces are prepared for microstructural analysis using an etchant called Villella - reagent ( $90 \mathrm{ml}$ ethanol, $2 \mathrm{gr}$ picric acid, $5 \mathrm{ml} \mathrm{HCl}$ ). Field emission scanning electron microscope (FESEM-Sigma 300) and energy dispersive X-ray (EDX) spectroscopy are used for the study of grain matrix. The macrograph of the selected part of the specimen is developed using stereo zoom microscope to identify clearly the WZ and HAZ boundaries in the weldment.

Hardness testing is performed across the weldment on a Vickers hardness testing machine following ASTM E 384-11e [8] with a constant load of $1 \mathrm{~kg}$, keeping $10 \mathrm{~s}$ as dwell time.

\section{Measurement of Welding Residual Stress}

\subsection{Experimental method}

The non-destructive $X$-ray diffraction method is used to measure the welding residual stress at different locations nearly on the surfaces (at 5 to 8 microns depth) of the butt welded P-91 plates. The fundamental of this measurement process is based on the analysis of diffraction of the incident ray due to the distorted lattice structure of the stressed area following Bragg's law given in the Equation 2.

$$
2 d_{h k l} \operatorname{Sin} \theta=n \lambda
$$

Where $d_{h k l}$ represents inter planner distance with Miller indices $(h \mathrm{kl}), \theta$ is the measurement of Bragg's angle, $n$ indicates the order of diffraction $(n=1,2,3 \ldots)$ and $\lambda$ is the wavelength of $X$-rays. 
The complete system consists of a light-emitting source with a detector to capture a limited part of diffracted X-rays. The Xrays are allowed to fall on the specimen at the area of interest and the values of diffraction angles are used to analyze the residual stresses. In the present study, residual stress measurement on welded samples of P-91 steel plates is done by the 'XSTRESS 3000' system with the modified $d\left(\sin ^{2} \psi\right)$ method, where the following parameters are considered as shown in Table 3.

Table 3. Parameters related with XRD measurement of stress.

\begin{tabular}{cc}
\hline Parameters & Measurement consideration \\
Radiation & $\mathrm{Cr}-\mathrm{K \alpha}$ \\
$2 \theta$ & $156.4^{0}$ \\
$2 \mathrm{~mm}$ & $20 \mathrm{~s}, 4 / 4$ tilts, $-40 / 40^{\circ}(\psi$ angles $)$ \\
Spot size & $211000 \mathrm{MPa}$ \\
Exposure time & 0.31 \\
\hline
\end{tabular}

The modified $d\left(\sin ^{2} \psi\right)$ method is based on the conventional $\sin ^{2} \psi$ approach having the following relationship [28].

$\frac{d \alpha \psi-d o}{d o}=\frac{1+v}{E} \sigma \cos ^{2} \alpha \sin ^{2} \psi+\frac{1+v}{E} \sigma \sin ^{2} \alpha-\frac{2 v}{E} \sigma$

In the stated equation (Equation 3), $d_{\alpha \psi}$ presents the inter planner distance at the inclination $\psi, d_{0}$ is the lattice spacing of unstressed area, $v$ and $E$ are the Poisson ratio and Young's Modulus respectively. The P91material is assumed to be isotropic in nature where $E_{h k l}=E$ and $v_{h k l}=v$. The variation in the lattice spacing indicates the induced strain in the sample from which the stress values are derived.

X-ray diffraction measurement technique reveals the magnitude of two principal stresses against two heat input which are discussed with relevant characteristics under "Results and discussion".

\section{Results and Discussion}

Both microstructural and mechanical characterizations of the welded specimen of P91 steel are carried out. The measurement of residual stresses and analysis of the same are also performed in this study. A suitable co-relationship has been developed among the microstructural changes, residual stresses, and mechanical properties.

\subsection{Microstructural analysis}

The microstructural evolution of the specimen is examined in order to find out the probable phase changes in a different part of the weldment as well as subsequent influences on the residual stresses and macro-hardness. SEM micrograph of $9 \mathrm{Cr}-$ $1 \mathrm{Mo}$ base metal (Figure 2) shows the presence of a fully tempered martensite structure with finely dispersed precipitates of carbides, $\mathrm{M}_{23} \mathrm{C}_{6}(\mathrm{M}=\mathrm{Cr}, \mathrm{Fe}, \mathrm{Mo})$ and carbo-nitrides, $\mathrm{MX}(\mathrm{M}=\mathrm{V}, \mathrm{Nb} \& \mathrm{X}=\mathrm{N}, \mathrm{C})$ around the grain boundaries. EDX spectrum of the base metal (Figure 2) has been taken at the selected places of accumulation of precipitates around the grain boundary derived through the SEM-images [14]. The presence of $C$ in the spectrum indicates the formation of carbides in the accumulation which are formed during tempering at a temperature below $A c_{1}$, after normalizing treatment.
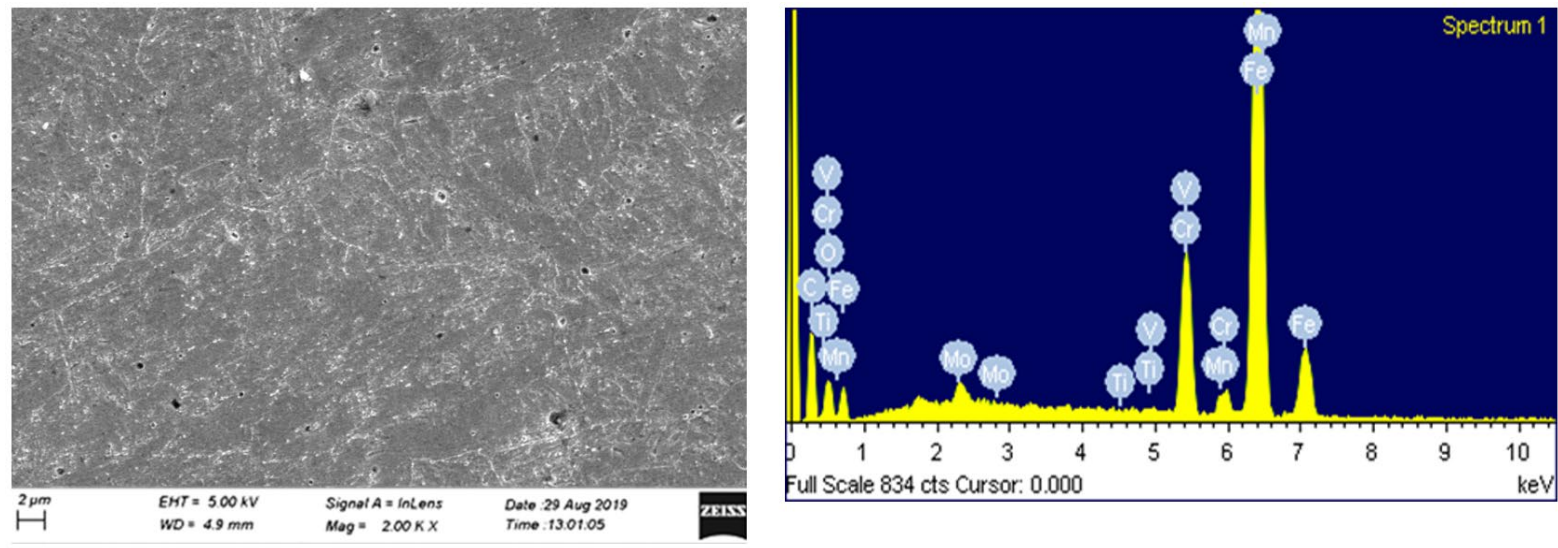

Figure 2. Base metal microstructure and EDX study of carbides. 
The microstructural changes in the post-weld heat treated (PWHT) welded specimen show (Figure 3) the significant growth of different grain matrix in WZ. The martensite formation is observed in the WZ along with ferritic structure. The formation of $\delta$-ferrite in WZ is partially observed in a discrete orientation with the accumulation of precipitates at the grain boundaries having heterogeneous sizes and morphologies with both the heat input. As a result of rapid cooling during welding, some of the $\delta$-ferrite is retained in the microstructure causing a detrimental effect on creep strength and fracture toughness [15]. $\mathrm{M}$. Abd El-Rahman et al. has conducted an extensive study on P91microstrure and reports that $\delta$-ferrite fraction increases due to heat input up to a certain value, less than $1.15 \mathrm{KJ} / \mathrm{mm}$ [29]. Beyond this heat input, $\delta$-ferrite fraction decreases with the subsequent addition of heat in the weld pool.
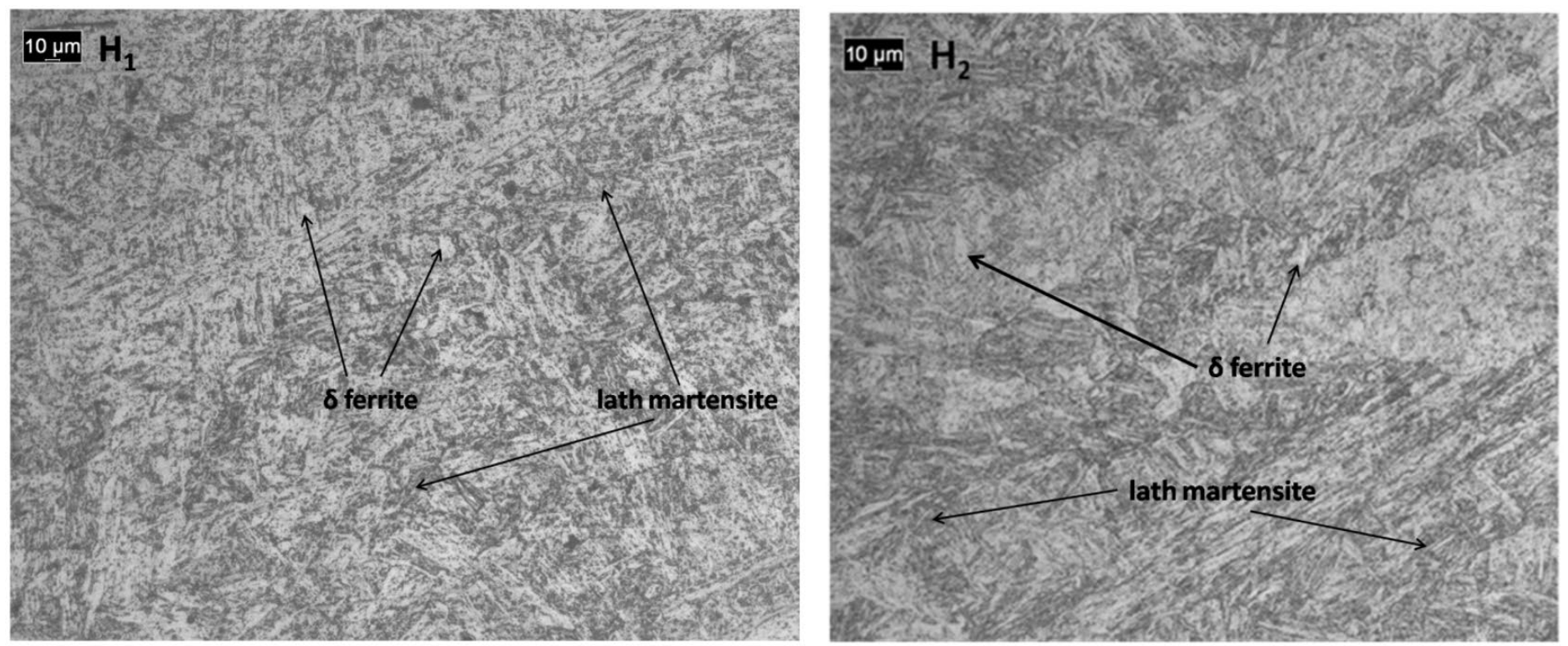

Figure 3. Optical micrograph of weld zone at different heat input condition.

The HAZ is critically identified with three possible different zones (Figure 4) and a decreasing trend in the density of precipitates is noted across the HAZ. It is worthy to mention that CGHAZ experiences the temperature far above the $A c_{3}$ which enhances the complete dissolution of precipitates and promotes the maxium austenite grain growth in this region. Due to the development of higher temperature in CGHAZ, the carbon atoms are diffused from ICHAZ to CGHAZ and the diffusion-rate may be accelerated with the rise in peak temperature [30].

FGHAZ, the grain refinement zone, reaches the temperature just above the $\mathrm{Ac}_{3}$ where softer martensitic formation takes place. The refinement of grains takes place through re-crystallization and pinning effect on austenites. Some precipitates, mainly carbides, are not fully dissolved in this region and hence, the growth of austenites is restricted to form relatively smaller and finer grains.

The ICHAZ shows the typical softening effect where peak temperature reaches above $\mathrm{Ac}_{1}$ but below the $A c_{3}$. In this region, ferrite is partially transformed into austenite on heating which is found to nucleate around lath-martensitic [29]. ICHAZ is the relatively softer zone in $9 \mathrm{Cr}-1 \mathrm{MoVNb}$ steel where type-IV cracking takes place due to creep exposure. The occurrence of such failure may be interrelated with the development of creep-cavities caused by the presence of coarser precipitates of $\mathrm{M}_{23} \mathrm{C}_{6}$ in ICHAZ with subsequently enhanced precipitation of Z-phase, a typical $\mathrm{Cr}(\mathrm{V}, \mathrm{Nb}) \mathrm{N}$ formation [11,31].

In the consequence of grain growth and subsequent grain refinement in $\mathrm{HAZ}$, the average size of previous austenite grains for CGHAZ, FGHAZ, and ICHAZ are found in descending order which are measured by adopting linear intercept methodology conforming to ASTM E112 [9] and presented in Table 4 [9].

Table 4. Average grain sizes and phases in HAZ.

\begin{tabular}{cccc}
\hline Heat input & CGHAZ & FGHAZ & ICHAZ \\
$2040 \mathrm{~J} / \mathrm{mm}$ & $11.3 \pm .69 \mu \mathrm{m}$ & $10.5 \pm .53 \mu \mathrm{m}$ & $9.8 \pm .71 \mu \mathrm{m}$ \\
\hline $2497.5 \mathrm{~J} / \mathrm{mm}$ & $11.7 \pm .57 \mu \mathrm{m}$ & $11.1 \pm .62 \mu \mathrm{m}$ & $10.3 \pm .48 \mu \mathrm{m}$ \\
\hline Phases & Tempered Martensite & Soft and slit martensite & $\begin{array}{c}\text { Untempered and over tempered } \\
\text { martensite }\end{array}$ \\
\hline
\end{tabular}

CGHAZ- coarse grain heat affected zone, FGHAZ- fine grain heat affected zone, ICHAZ- intercritical heat affected zone. 

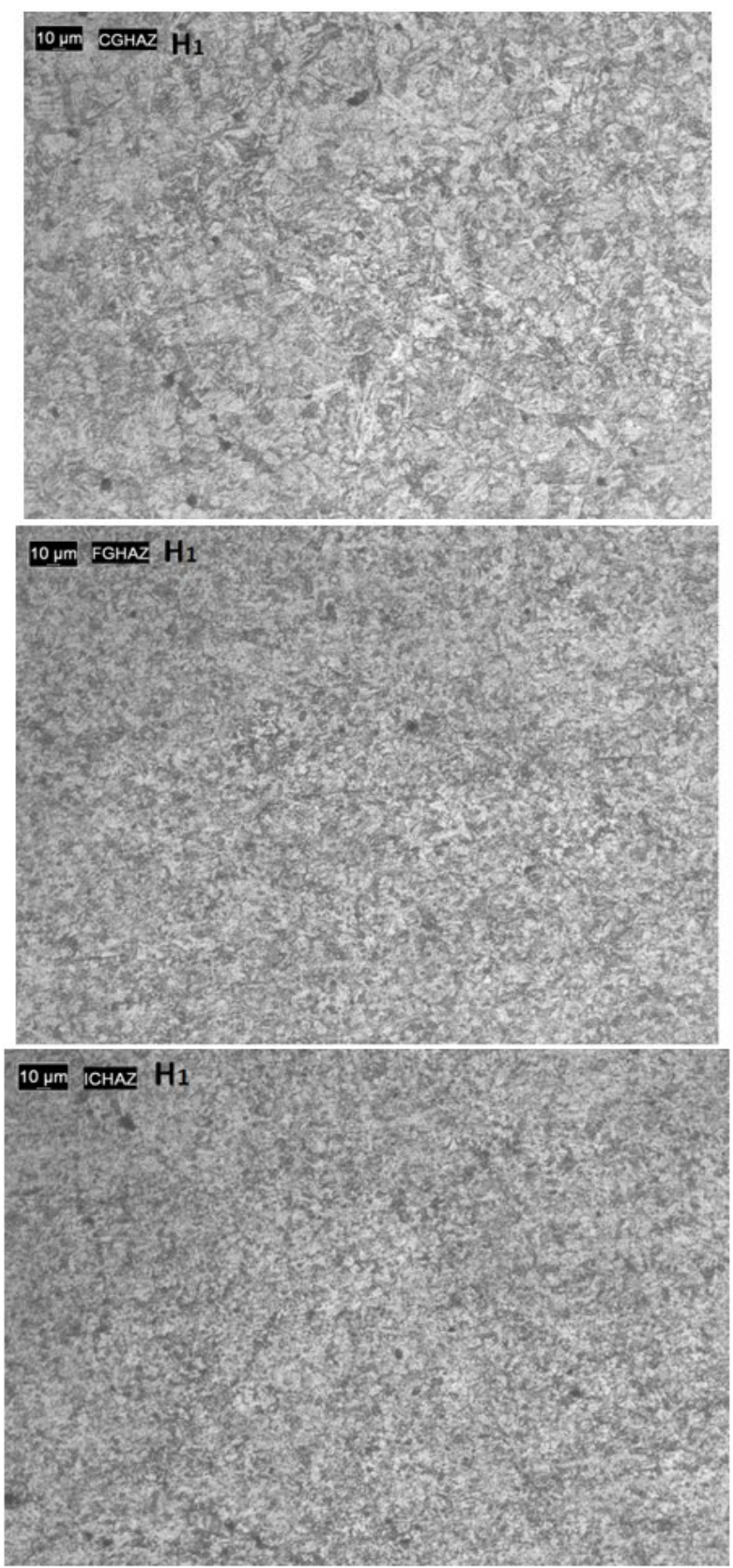
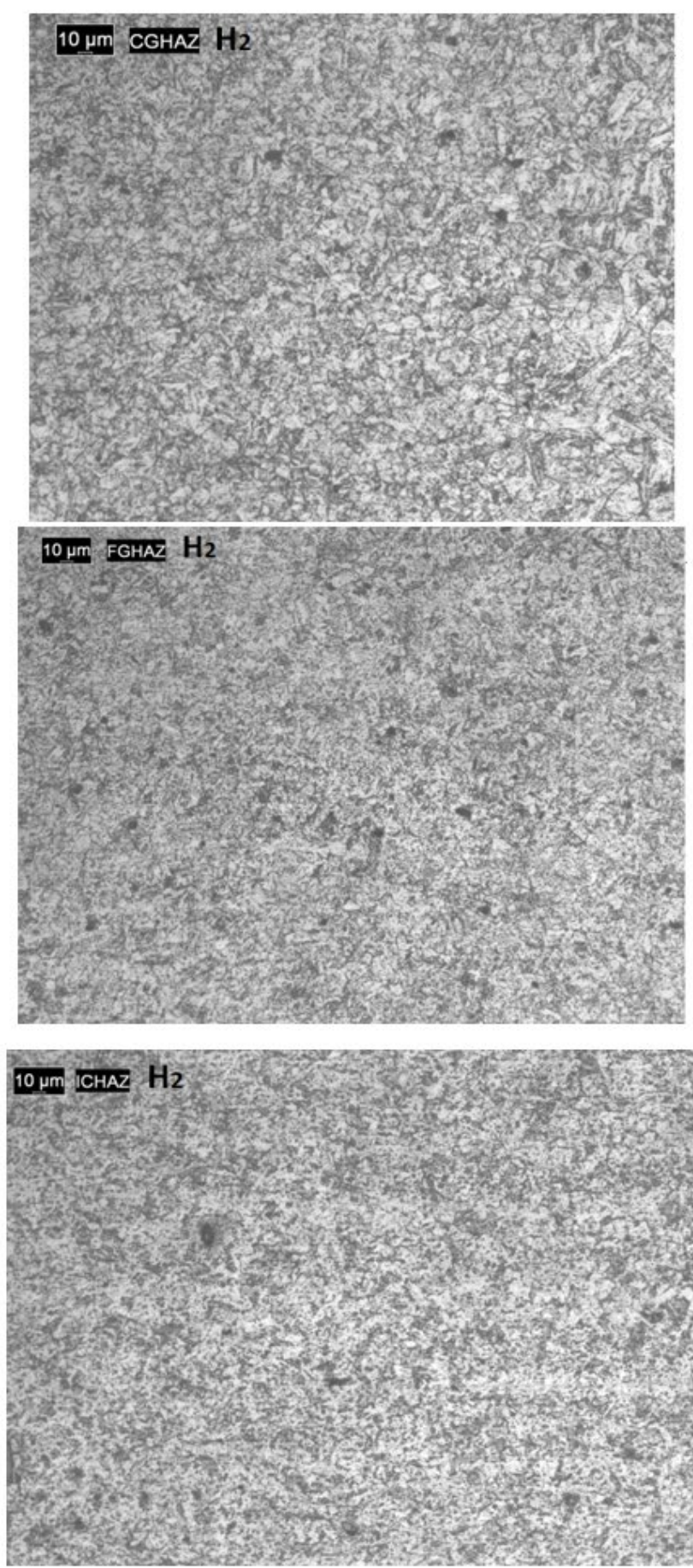

Figure 4. Optical micrograph of HAZ with low and high heat input conditions.

\subsection{Weldment characterization}

Figure 5 depicts the optical macrograph of the weldment of both the specimen after the heat treatment. The weld zone and HAZ in the two specimens are found to be influenced by the process parameters of SAW owing to variation in heat input and significant differences in weld bead characteristics are observed. The bead width seems to be slightly wider on the upper side having a small conical bead profile at the bottom with low heat input condition. The bead profile with high heat input shows a typical conical reinforcement on the top and bottom surfaces. This may happen due to the deposition of more molten weld metal in WZ with high heat flux and arc force which is generated in the region with relatively low welding speed. A larger HAZ is observed in the specimen with higher heat input. The profile of WZ through depth reflects almost axisymmetric curvature in both the specimen which has an influence on the distribution of residual stresses and addressed later. 

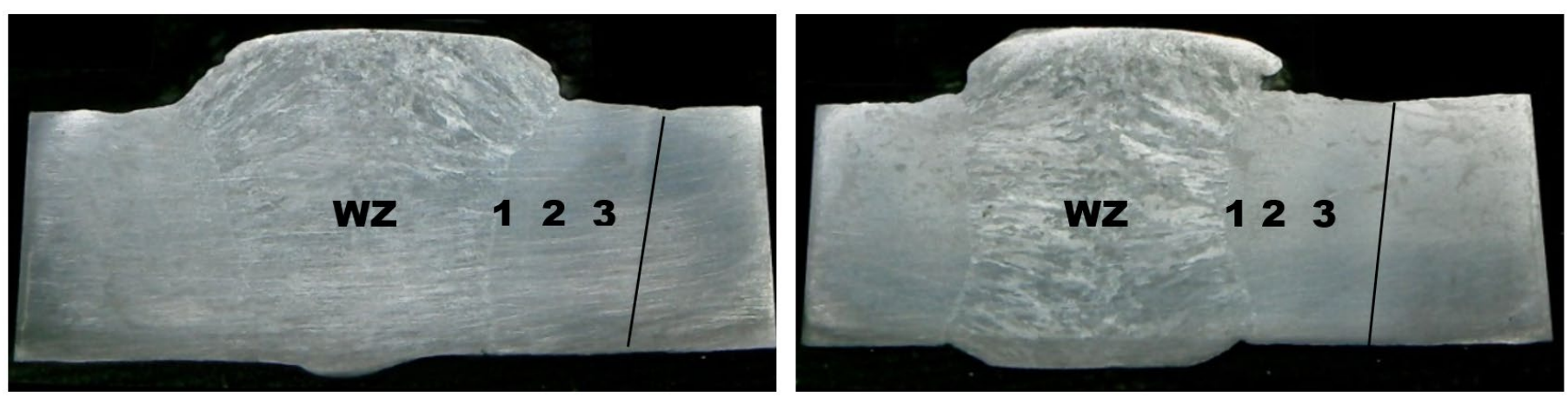

Figure 5. Macrograph of the welded specimen (a) low heat input; (b) high heat input(1- CGHAZ, 2-FGHAZ, 3-ICHAZ).

\subsection{Thermal profiles of the weldment}

Figure 6 shows the time vs temperature relationship in the form of a curve as obtained near the FZ through thermocouple from the specimen of P91steel. The peak temperatures are recorded as $943^{\circ} \mathrm{C}$ and $857^{\circ} \mathrm{Cin}$ case of high and low heat input respectively which shows a deviation of $\pm 4 \%$ with theoretical predictions. The critical cooling time $\left(\Delta \mathrm{t}_{8 / 5}\right) \operatorname{shows} 31 \mathrm{~s}$ and $26 \mathrm{~s}$ with a cooling rate $9.67^{\circ} \mathrm{C} / \mathrm{s}$ and $11.53^{\circ} \mathrm{C} / \mathrm{s}$ correspondingly as derived from the curve against two specific conditions. The CCT diagram (Figure 7) reflects the phases likely to be developed through continuous cooling where cooling rates like $9.67^{\circ} \mathrm{C} / \mathrm{s}$ and $11.53^{\circ} \mathrm{C} / \mathrm{s}$ indicate the substantial presence of martensite as prominent phases. However, it is difficult to get the deterministic idea from the CCT diagram regarding the partial or other modes of dissolution of precipitates (carbides, carbonitrides etc.) in the grain-matrix. In spite of the fact that the temperature range related to the peritectic zone of reaction $(L+\delta=\gamma)$ is above the range of critical temperature, still, the $\Delta t_{8 / 5}$ may be regarded as an indicator of detained $\delta$-ferrite as process outcome. Conceptionally, the austenite cooling at a faster rate may not be able to develop $\gamma$-phase homogeneously through diffusion which can be predicted from the trailing part of the curve under $\Delta \mathrm{t}_{8 / 5}$ and the same is verified alternatively on the basis of heat input [29]. It is observed that the difference in the values of $\Delta \mathrm{t}_{8 / 5}$ with both the heat input indicates the higher cooling rate with low heat input. Interestingly, both the cooling rates indicate the same type of phases as shown in the CCT diagram related to the microstructural evolution in this region.

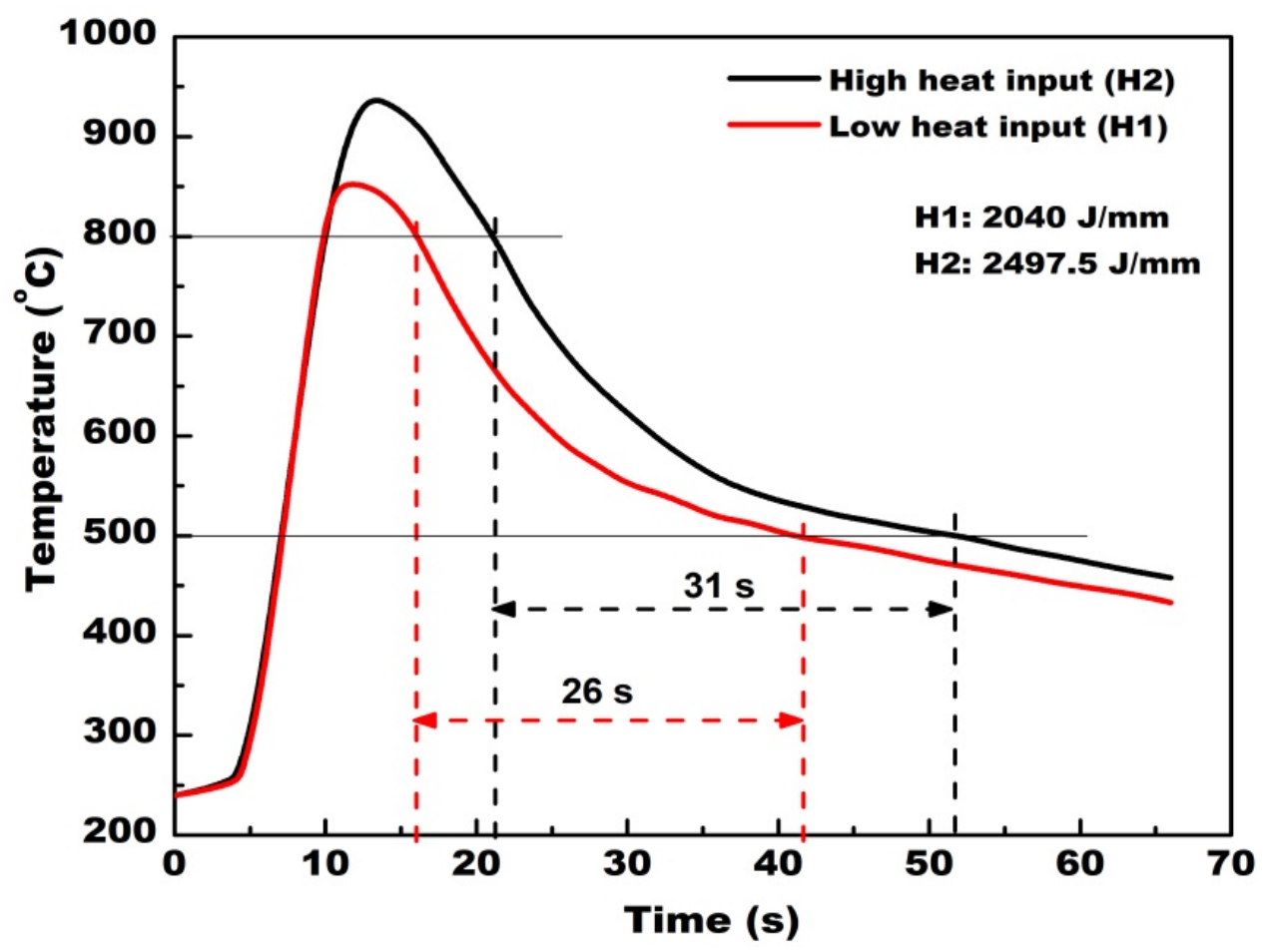

Figure 6. Time vs temperature plot with two heat inputs. 


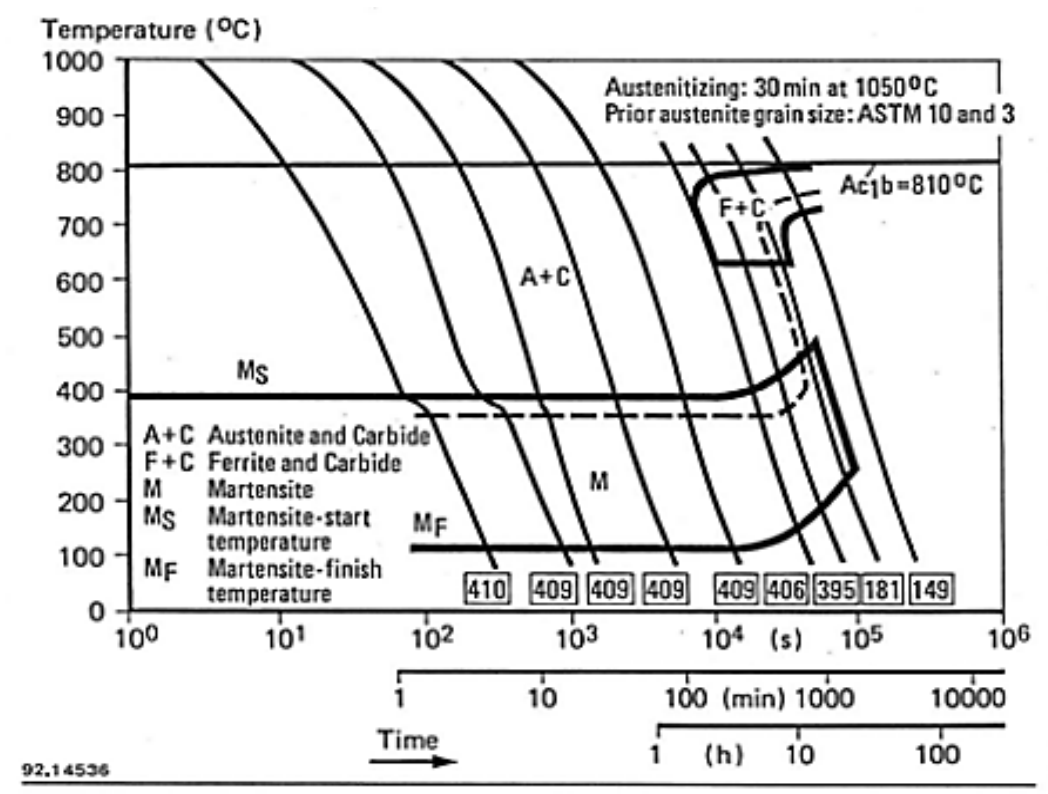

Figure 7. CCT diagram of P91 steel [32].

\subsection{Residual stress}

Figure 8 shows the distribution of welding residual stresses with respect to the welding direction, identified as the longitudinal and transverse component, measured by the X-ray diffraction method at weld zone (WZ), heat affected zone (HAZ) and base metal (BM) on the welded specimen of P-91 steel with two different heat inputs. The longitudinal stress profiles $\left(\sigma_{x}\right)$ exhibit the compressive stresses about $118.5 \mathrm{MPa}$ and $142.4 \mathrm{MPa}$ in the weld zone for two heat input. Welded plates with higher heat input $(2497.5 \mathrm{~J} / \mathrm{mm})$ shows the less compressive stresses to be developed in WZ in comparison with low heat input $(2040 \mathrm{~J} / \mathrm{mm})$ specimen. Basically, the tempered martensite in P91 steel is transformed into austenite during heating which is supposed to be happened between the temperature range of $A_{1}\left(820^{\circ} \mathrm{C}\right)$ and $\mathrm{A}_{3}\left(920^{\circ} \mathrm{C}\right)$ [10]. Such type of austenitic transformation causes a reduction in volume due to the inherent property of the change in crystallographic-structure [33]. During rapid cooling of the same, at a specific range of low temperature, austenite transforms to martensite and volume of the material increases [10,33]. The displacive mode of martensite transformation at low temperature shows more significant influence on compressive stresses than austenite transformation as the later one happens at higher temperature where mechanical properties are essentially weaker [10,33]. Moreover, the cooling rate in the weld thermal cycle with different heat input influences the martensite formation and the less heat input $(2040 \mathrm{~J} / \mathrm{mm})$ promotes the more martensitic structure. The effect of such phase transformation on the residual stresses at the low-temperature range is critically explained by Silva et al. and Yaghi et al. in two separate studies [10,34].
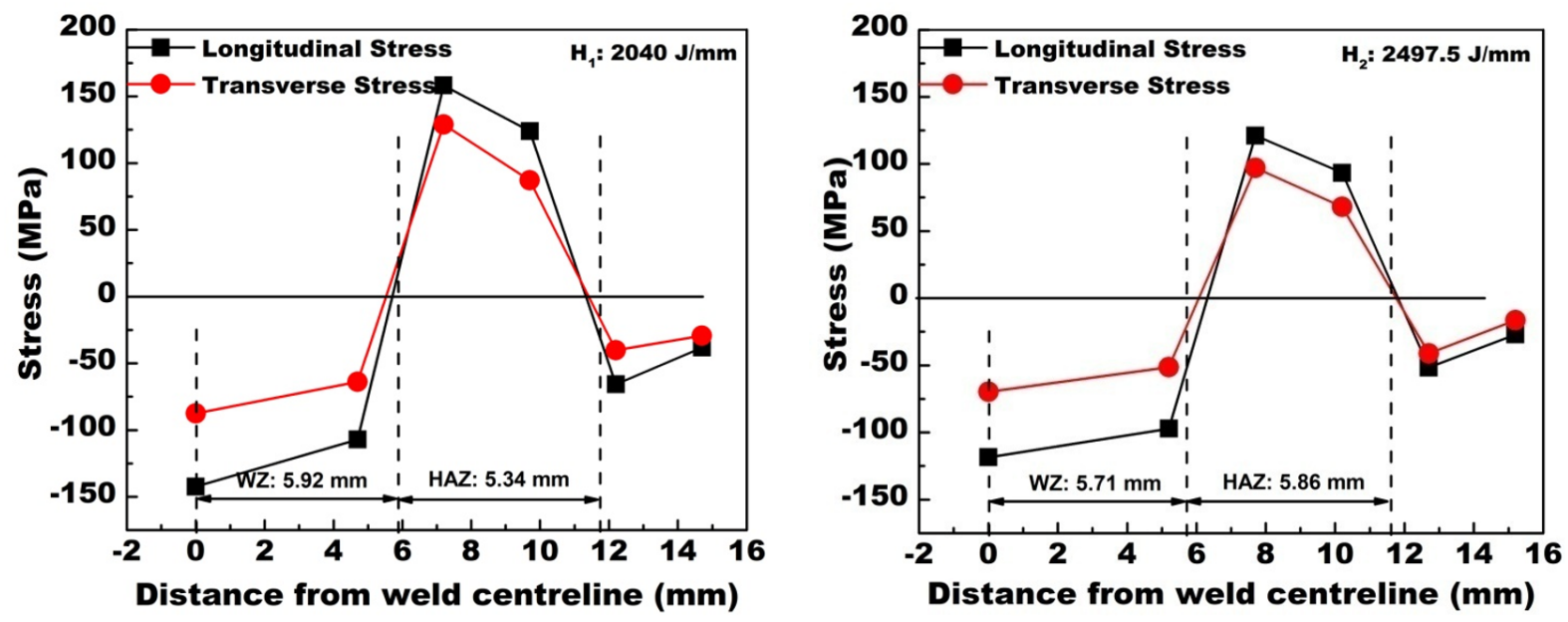

Figure 8. Residual stress distribution from weld centerline. 
Residual stress profiles of the transverse component $\left(\sigma_{y}\right)$ show the lower values of compressive stresses in both the specimen. The maximum magnitudes of compressive stresses of $69.7 \mathrm{MPa} \& 87.5 \mathrm{MPa}$ are observed in the weld zone. With both the heat input, the tensile stresses are detected near the boundary of CGHAZ with WZ which seems to alter its nature from tensile to compressive at the end of HAZ. The partial dissolution of precipitates and the development of transformed softer, slit martensite may be attributed to such occurrence of stress alteration.


Figure 9. Layer formation with grids for two specimen.

Layer analysis by the grid-formation of the weld zone (Figure 9) may adhere to the development of residual stresses through which a comprehensive assumption can be done on the nature of stresses to be distributed on the surfaces of the plate as well as through depth in P91 plates. It appears from the figure (Figure 9) that the upper layer width of FZ (layer 1) is more than that of the middle layer (layer 2 ) in both the specimen. It confirms that the area pertaining to the distribution of compressive stresses in layer 1 is larger than layer 2 and the same can be compared to layer 3 . However, this is an approximated analytical approach to predict the nature of stress distribution which can be performed with more accuracy increasing the number of grids $\left(n_{i j}=1,2,3 \ldots k_{i j}\right)$ where $n_{i j}$ indicates the grid-number in rows and column, $k_{i j}$ relates to any positive integer considered accordingly for rows and column. The suitable matrix thus developed may be related to FEA and the outcome regarding the nature of stress-distribution can be verified by adopting a suitable measurement process, like an incremental hole drilling method, where stresses at each layer can be experimentally evaluated. The position of the holes accordingly can be selected on the surface for through-depth analysis (Z-axis) of residual stresses in P91 plates from the grids of the macrograph.

Conforming to layer analysis, it is observed from the stress profiles that the central part of the fusion zone experiences the maximum compressive stresses with both the heat input which decreases up to the further extent of the WZ on both sides. A part of HAZ reflects the presence of tensile stresses and the magnitude of tensile stresses are observed to be more than compressive stresses (Figure 8). It is worthy to mention that a small part of the base metal near to ICHAZ exhibits the typical presence of a compressive type of residual stresses with low magnitudes in both the specimen.

\subsection{Hardness analysis}

Figure 10 represents the macro-hardness profiles of the P-91 steel specimen with two heat inputs on the transverse section of the weldment. In both cases, the maximum hardness is observed in WZ and a subsequent decrease in hardness values is recorded in CGHAZ, FGHAZ, and ICHAZ respectively. As the martensite formation decreases with an increase in heat input, the hardness profile indicates the less hardness values in the range of $287 \mathrm{HV}$ to $310 \mathrm{HV}$ in FZ with higher input compared to $306 \mathrm{HV}$ to $320 \mathrm{HV}$ with low heat input. The phenomenon of increased hardness in fusion zone may be interrelated to the tempered martensitic structure as a consequence of austenite cooling in WZ with the formation of two possible precipitates like $\mathrm{M}_{23} \mathrm{C}_{6}$ and $\mathrm{MX}$ at the grain boundaries. Further, the dissolution of precipitates in the solid solution, specially carbides, either partially or fully, increases the content of carbon and an increased amount of carbon concretation in CGHAZ leads to the harder martensite formation as compared to FGHAZ and ICHAZ. Hence, FGHAZ shows a decrease in hardness values due to the partial dissolution of formed precipitates and the formation of low carbon softer martensite from the fine-grained austenitic structure in this region. The ICHAZ exhibits the least hardness values owing to the softening effect of this part which can be rationalized from the viewpoint of the less precipitation effect. Mansilla Yanet et al. relates the minimum hardness in ICHAZ with the decrease in the precipitation density in P-91 steel specimen [35]. 


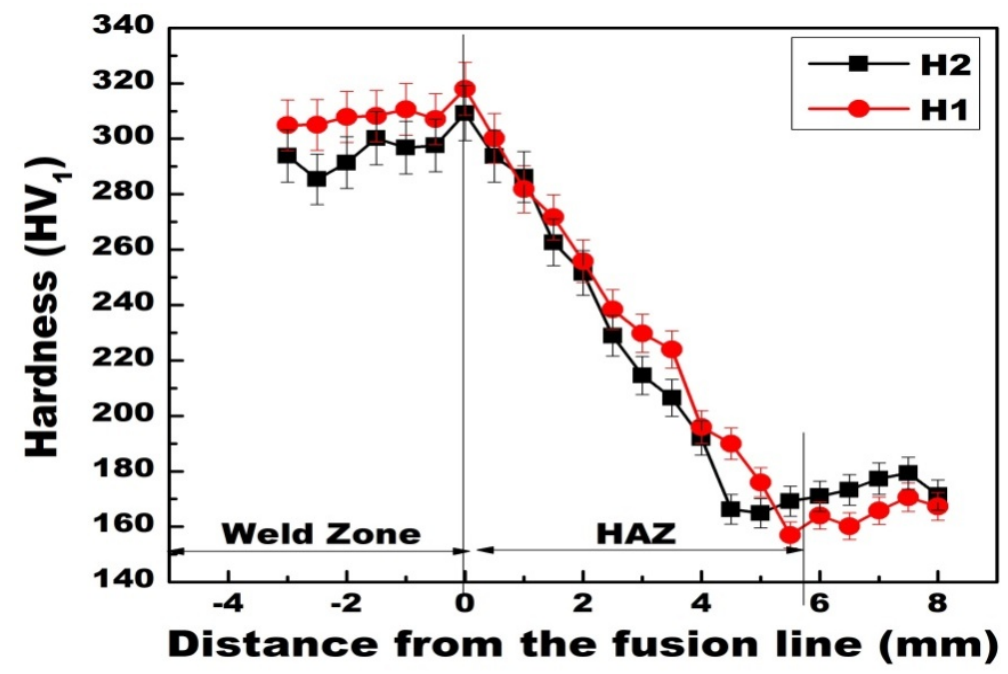

Figure 10. Hardness profile of weldment.

\subsection{Correlation among microstructure, residual stress, and hardness}

The heterogeneous nature of martensite formation, temperature dependent influence of precipitates and involvent of other variables, strongly affect the variation in residual stresses and hardness of P91 steel. Figure 8 and Figure 10 depict the fact that the higher magnitudes of compressive stresses and the maximum hardness values are observed in the WZ of both the specimen of P91 steel plates. The successive development of mainly martensite layers generates the higher magnitudes of compressive stresses in WZ where maximum hardness values are observed. In fact, from the figures, there is no significant relationship found between the stress characteristics and the macro-hardness throughout the length of HAZ. However, a diminishing nature of compressive stresses followed by a high tensile stress is observed in HAZ whilst a nonlinear decreasing trend in hardness is noted in the same region. The effect of grain coarsening and refinement have a major contribution to influence the hardness profile in HAZ [14,27]. The presence of tensile stresses in the ICHAZ comprising of low hardness values and type-IV failure through creep rupture are correlated with the viewpoint of accelerated deterioration of creep behavior through the initiation of creep-cavity in the affected region [36]. An insignificant part of BM near the ICHAZ which is over tempered in true nature shows the presence of very small magnitudes of compressive stresses as well as low hardness values.

\subsection{Mutual numerical characterization of the structural phenomenon}

Conceptually, the progressive formation of martensite through rapid austenite cooling generates maximum volumetric strain $\left(\varepsilon_{\mathrm{vol}}\right)$ at the central part of the weld zone due to which this area experiences the maximum compressive stresses. At the same time, WZ experiences the optimal range of hardness. The sense of equilibrium in the structure is maintained by tensile residual stresses generated in the nearby area, particularly in FGHAZ and ICHAZ. The effect of martensitic transformation on related volume change $(\Delta v)$ is critically represented by a deterministic type of relationship to avoid complexity in the calculation as shown in Figure 11. As the rate of carbon diffusion is not uniform during cooling and hence, unorthodox multidirectional type martensite is formed as a metastable phase. The stochastic nature of assumption for such a phenomenon may be made within a range of possible considerations of dimensions based on a suitable matrix to achieve better accuracy for dimensional analysis. The optimal size of martensite may be approximated from the equation $\left[G_{o p t}\right]=\left[G_{\text {ave }}\right]\left[G_{T}\right]$. Here, $\left[G_{o p t}\right]$ relates to the optimal martensite dimension matrix, $\left[G_{\text {ave }}\right]$ indicates the average grain dimension matrix and $\left[\mathrm{G}_{\mathrm{T}}\right]$ indicates the related transformation matrix. The possible average transformations of martensite at different directions may be taken into consideration under[ $\mathrm{G}_{\mathrm{T}}$ ]. The outcome may be used for modeling of martensite structure with better accuracy against a particular range of heat input. Figure 8 explicitly indicates the presence of high compressive stresses with longitudinal $\left(\sigma_{x}\right)$ and transverse $\left(\sigma_{y}\right)$ component at the weld center line and an increase in $62.85 \%$ and $70.01 \%$ are observed in compressive stresses in longitudinal $\left(\sigma_{x}\right)$ component with respect to transverse $\left(\sigma_{y}\right)$ component with low and high input respectively. Interestingly, average hardness has been found to increase about $58 \pm 4 \%$ in WZ with respect to the base metal. The linear dimension of average grain size exhibits higher value in FZ. It is observed that a decreasing trend exists in tensile stresses about $21 \%$ and $32.4 \%$ with longitudinal $\left(\sigma_{x}\right)$ and transverse $\left(\sigma_{y}\right)$ component with low heat input in FGHAZ and ICHAZ. The same trend is seen with high heat input where tensile stresses have decreased by about $22.87 \%$ and $29.89 \%$ with longitudinal $\left(\sigma_{x}\right)$ and transverse $\left(\sigma_{y}\right)$ component respectively. 


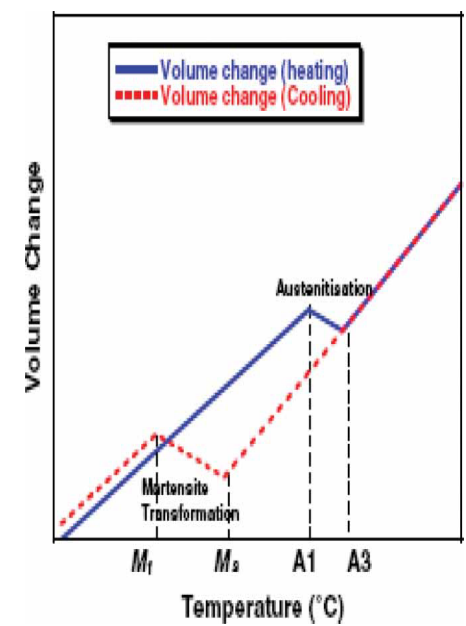

Figure 11. Effect of volume change for martensitic transformation [10].

\section{Conclusions}

In this study, the microstructural analysis of P-91 steel and its subsequent influence on the measured stress characteristics and hardness profiles are examined with the following important observations.

- The base metal microstructure of P91plates reveals the presence of martensitic matrix and the EDX study on the accumulation at the grain boundaries shows the presence of precipitates of carbides;

- The patches of $\delta$-ferrite are observed in WZ with the both heat input. The increase in heat input from $2040 \mathrm{~J} / \mathrm{mm}$ to $2497.5 \mathrm{~J} / \mathrm{mm}$ shows the approximated $3.53 \%, 5.71 \%$ and $5.1 \%$ increase in average grain sizes in CGHAZ, FGHAZ and ICHAZ respectively in the weldment of P91;

- The conical bead geometry at the top and bottom surfaces of P91 plates is observed with higher heat input in spite of having relatively less current of 450A. Due to having comparatively low welding speed, the volume of weld pool generated per unit time with the longer duration of arc force may develop such bead geometry;

- The longitudinal stress profiles exhibit higher tensile stresses and compressive stresses in both the specimen. An increase of $20.16 \%$ in compressive stresses at weld centerline is observed with less heat input where a variation of $11.4 \%$ and $7.02 \%$ in tensile stresses are recorded with low and high input conditions;

- Hardness profiles show a decreasing trend of macro hardness from WZ to ICHAZ in both the specimen and an increase in the values of macro-hardness are critically noted as approximately $6.62 \%$ in WZ due to variation in heat input. The soft zone related to ICHAZ might be susceptible to type-IV cracking under the influence of tensile stresses. High compressive stress magnitudes in WZ are correlated with high hardness values and larger grain sizes. The specimen with high heat input exhibit lower hardness and less compressive stresses in WZ.

\section{References}

[1] Withers PJ, Bhadeshia HKDH. Overview residual stress Part 2 - nature and origins. Materials Science and Technology. 2001;17(4):366375. http://dx.doi.org/10.1179/026708301101510087.

[2] Francis JA, Bhadeshia HKDH, Withers PJ. Welding residual stresses in ferritic power plant steels. Materials Science and Technology. 2007;23(9):1009-1020. http://dx.doi.org/10.1179/174328407X213116.

[3] Parmar RS. Welding engineering and technology. Delhi: Khanna Publishers.

[4] Roy J, Rai RN, Saha SC. Effect of $\mathrm{TiO}_{2}$ enriched fluxes on the bead geometry, grain size and hardness in submerged arc welds. International Journal of Materials \& Product Technology. 2018;56(4):313-325. http://dx.doi.org/10.1504/IJMPT.2018.092073.

[5] Roy J, Majumder A, Saha SC, Rai RN. Optimization of the effect of welding heat input on the microstructure and mechanical properties of submerged arc welded joints by fuzzy-based multiobjective threshold acceptance algorithm. Proceedings of the Institution of Mechanical Engineers. Part B, Journal of Engineering Manufacture. 2013;227(12):1830-1840. http://dx.doi.org/10.1177/0954405413495013.

[6] Roy J, Rai RN, Saha SC. Evaluation of microstructure and mechanical properties of P91steel weldment due to addition of boron trioxide into flux during submerged arc welding. Welding in the World. 2018;62:1-8.

[7] Tanaka, J., Kitada, T., Nagarwa, Y., Kunisada, Y. and Nakagawa, H. Element transfer behavior during submerged arc welding. Proceedings of International Conference on Weld Pool Chemistry and Metalurgy, 1980;279-288. 
[8] Roy J, Chakraborti R, Rai R, Saha S. Studies on microstructure and mechanical properties of modified 9Cr-1Mo (P91) steel in submerged arc welding with TiO2-enriched fluxes. Journal of the Brazilian Society of Mechanical Sciences and Engineering. 2019;41(10):468. http://dx.doi.org/10.1007/s40430-019-1968-4.

[9] Roy J, Rai RN, Saha SC. Evaluation of microstructure and mechanical properties of P-91 steel weldment due to addition of boron trioxide into flux during submerged arc welding. Welding in the World. 2018;62(1):1-8. http://dx.doi.org/10.1007/s40194-017-0515-0.

[10] Yaghi AH, Hyde TH, Becker AA, Sun W. Numerical simulation of P91 pipe welding including the effects of solid-state phase transformation on residual stresses. Proceedings of the Institution of Mechanical Engineers, Part L: Journal of Materials: Design and Applications. 2007;221(4):213-224.

[11] Laha K, Chandravathi KS, Parameswaran P, Rao KBS, Mannan SL. Characterization of microstructures across the heat-affected zone of the modified $9 \mathrm{Cr}-1 \mathrm{Mo}$ weld joint to understand its role in promoting type-IV cracking. Metallurgical and Materials Transactions. A Physical Metallurgy and Materials Science. 2007;38(1):58-68. http://dx.doi.org/10.1007/s11661-006-9050-0.

[12] Golanski G, Jasak J, Zielinski A, Kolan C, Urzynicok M, Wieczorek P. Quantitative analysis of stability of $9 \%$ Cr steel microstructure after long term aging. Archives of Metallurgy and Materials. 2017;62(1):263-271. http://dx.doi.org/10.1515/amm-2017-0040.

[13] Czyrska-Filemonowicz A, Zielinska-Lipiec A, Ennis PJ. Modified 9\% Cr steels for advanced power generation: microstructure and properties. AMME. 2006;19(2):43-48.

[14] Pandey C, Mahapatra MM. Effect of heat treatment on microstructure and hot impact toughness of various zones of P91 welded pipes. Journal of Materials Engineering and Performance. 2016;25(6):2195-2210. http://dx.doi.org/10.1007/s11665-016-2064-x.

[15] Li X, Callibrat MT, Lejeail Y. Study of modified 9Cr-1Mo welds. International Nuclear Information System. 2006;43(12):64-92.

[16] Chakrabarti R, Biswas P, Saha SC. A review on welding residual stress measurement by hole drilling technique and its importance. Journal of Welding and Joining. 2018;36(4):75-82. http://dx.doi.org/10.5781/JWJ.2018.36.4.9.

[17] Kim S-H, Kim J-B, Lee W-J. Numerical prediction and neutron diffraction measurement of the residual stresses for a modified $9 \mathrm{Cr}-1 \mathrm{Mo}$ steel weld. Journal of Materials Processing Technology. 2009;209(8):3905-3913. http://dx.doi.org/10.1016/j.jmatprotec.2008.09.012.

[18] Ilker Yelbay H, Cam I, Hakan Gür C. Non-destructive determination of residual stress state in steel weldments by Magnetic Barkhausen Noise technique. NDT \& E International. 2010;43(1):29-33. http://dx.doi.org/10.1016/j.ndteint.2009.08.003.

[19] Lin J, Ma N, Lei Y, Murakawa H. Measurement of residual stress in arc welded lap joints by cosa X-ray diffraction method. Journal of Materials Processing Technology. 2017;243:387-394. http://dx.doi.org/10.1016/j.jmatprotec.2016.12.021.

[20] Li S, Ren S, Zhang Y, Deng D, Murakawa H. SendongRen, Yanbin Zhang, Dean Dang, HidekazuMurakawa "Numerical investigation of formation mechanism of welding residual stress in P92 steel multi-pass joints". Journal of Materials Processing Technology. 2017;244:240-252. http://dx.doi.org/10.1016/j.jmatprotec.2017.01.033.

[21] Paddea S, Francis JA, Paradowska AM, Bouchard PJ, Shibli IA. Residual stress distributions in a P91 steel-pipe girth weld before and after post weld heat treatment. Materials Science and Engineering A. 2012;534:663-672. http://dx.doi.org/10.1016/j.msea.2011.12.024.

[22] Ishigami A, Roy MJ, Walsh JN, Withers PJ. The effect of the weld fusion zone shape on residual stress in submerged arc welding. International Journal of Advanced Manufacturing Technology. 2017;90(9-12):3451-3464. http://dx.doi.org/10.1007/s00170-016-9542-z.

[23] Kundu A, Bouchard PJ, Kumar S, Dey GK. Characterisation of residual stress in electron beam welded P91 plates by neutron diffraction. International Journal of Metallurgical Engineering. 2013;2(1):79-84.

[24] Venkata KA, Kumar S, Dey HC, Smith DJ, Bouchard PJ, Truman CE. Study on the effect of post weld heat treatment parameters on the relaxation of welding residual stresses in electron beam welded P91 steel plates. Procedia Engineering. 2014;86:223-233. http://dx.doi.org/10.1016/j.proeng.2014.11.032.

[25]Arun Kumar S, Mahadevan S, Raja MK, Purnachandra C Rao B, Albert SK, Murugan S. Comparison of welding induced residual stresses in austenitic and ferritic steel weld joints. In: Proceeding of the Indian National Seminar \& Exhibition on Non-Destructive Evaluation NDE 2015 (NDE-India 2015); 2015 November 26-28; Hyderabad, India. India: Indian Society for Non Destructive Testing; 2015. p. 1-6.

[26] Maduraimuthu V, Vasudevan M, Muthupandi V, Bhaduri AK, Jayakumar T. Effect of activated flux on the microstructure,mechanical properties, and residual stresses of modified 9Cr-1Mo steel weld joints. Metallurgical and Materials Transactions B, 43B, 123-132. https://doi.org/10.1007/s11663-011-9568-4.

[27] Silva CC, Assis JT, Philippov S, Farias JP. Residual stress, microstructure and hardness of thin-walled low-carbon steel pipes welded manually. Materials Research. 2016;19(6):1215-1225. http://dx.doi.org/10.1590/1980-5373-mr-2016-0217.

[28] Xi Y, Gao K, Pang X, Yang H, Xiong X, Li H, et al. Film thickness effect on texture and residual stress sign transition in sputtered TiN thin films. Ceramics International. 2017;43(15):11992-11997. http://dx.doi.org/10.1016/j.ceramint.2017.06.050.

[29] Abd El-Rahman Abd El-Salam M, El-Mahallawi I, El-Koussy MR. Influence of heat input and post-weld heat treatment on boiler steel P91 (9Cr-1Mo-V-Nb) weld joints Part 1 - Microstructure. International Heat Treatment and Surface Engineering. 2013;7(1):23-31. http://dx.doi.org/10.1179/1749514813Z.00000000050. 
[30] Abd El-Rahman Abd El-Salam M, El-Mahallawi I, El-Koussy MR. Influence of heat input and post-weld heat treatment on boiler steel P91 (9Cr-1Mo-V-Nb) weld joints Part 2 - Mechanical properties. International Heat Treatment and Surface Engineering. 2013;7(1):32-37. http://dx.doi.org/10.1179/1749514813Z.00000000051.

[31] Maruyama K, Sawada K, Koike J. Advances in physical metallurgy and processing of steels. Strengthening mechanisms of creep resistant tempered martensitic steel. ISIJ International. 2001;41(6):641-653. http://dx.doi.org/10.2355/isijinternational.41.641.

[32] Huysmans S, Vekeman J. A challenging weld repair of Grade 91 tubing by avoiding PWHT. Energy Materials. 2009;4(2):76-83. http://dx.doi.org/10.1179/174892310X12811032100033.

[33] Yaghi AH, Hyde TH, Becker AA, Sun W. Thermo mechanical modelling of weld microstructure and residual stresses in P91 steel pipe. Energy Materials. 2009;4(3):113-123. http://dx.doi.org/10.1179/174892310X12779109287084.

[34] Silva CC, Miranda HC, Novotny L, Fonseca MC. The welding of dissimilar joints with low temperature martensitic transformation filler material. Soldegem and Inspecao. 2018;23(4):1-12.

[35] Yanet M, Mónica Z. Microstructure characterization of heat affected zone in single pass welding in $9 \mathrm{Cr}-1 \mathrm{Mo}$ steels. Procedia Materials Science. 2015;8:904-913. http://dx.doi.org/10.1016/j.mspro.2015.04.151.

[36] Francis JA, Mazur W, Bhadeshia HKDH. Type IV cracking in ferritic power plant steels. Materials Science and Technology. 2006;22(12):1387-1394. http://dx.doi.org/10.1179/174328406X148778. 